\title{
Development of activated carbon using one step carbonization and activation reaction by polymer blend method
}

\author{
S. Manocha*a, Parth Joshi ${ }^{\mathrm{b}}$, Amit Brahmbhatt $^{\mathrm{c}}$, Amiya Banerjee $^{\mathrm{c}}$, \\ Snehasis Sahoo' ${ }^{\text {, L.M.Manocha }}{ }^{\mathrm{C}}$ \\ aUniversity School of Basic \& Applied Sciences, G.G.S. Indraprastha University \\ Sector-16C, Dwarka, New Delhi 110075 \\ ${ }^{\mathrm{b}}$ Department of Applied Physics, S V National Institute of Technology, Surat \\ $-395007$ \\ 'Department of Materials Science, Sardar Patel University, \\ Vallabh Vidyanagar -388120 \\ E-mail: parthjoshi16@rediffmail.com
}

Keywords: Activated carbon, polymer blend method, surface area, average pore diameter

\begin{abstract}
In the present work, a one step carbon activation process was developed by stabilized poly-blend. It is carbonized in nitrogen atmosphere and activated in steam in one step for known interval of times to enhance the surface area and develop interconnected porosity. The weight-loss behavior during steam activation of stabilized poly-blend at different temperatures, surface area and pore size distribution were studied to identify the optimum synthesis parameters. The results of surface characteristics were compared with those of activated carbon prepared by carbonization and activation in two steps. It was found that activation temperature has profound effect on surface characteristics. As activation temperature was raised from $800^{\circ} \mathrm{C}$ to $1150^{\circ} \mathrm{C}$, surface area of activated carbon increased about three times. In addition to surface area, average pore diameter also increases with increasing activation temperature. Thus, activated carbon with high percentage of porosity and surface area can be developed by controlling the activation temperature during activation process.
\end{abstract}

\section{INTRODUCTION}

Activated carbon is a predominantly amorphous solid carbon material with highly developed internal surface area, interconnected porous structure and high degree of surface reactivity. These unique characteristic properties make activated carbon materials very versatile adsorbent material for adsorption of both gaseous and liquid phase molecules. Therefore, activated carbons are useful adsorbents for removing pollutants of different sizes both in liquid and gaseous phase [16].Advantages of activated carbon materials as adsorbents are that the treated effluent is of high quality, design of the process is simple and operation of process developed or adopted is easy.

Activation produces a distribution of internal pores and affects the carbon surface generally to enhance its adsorptive capacity. Thus, by varying activation conditions, differences of the internal surfaces can be induced even for materials that appear to be identical.

Physical activation is a process by which the carbonized product develops porous structure of molecular dimensions and extended surface area on heat treatment in the temperature range of $800-1000^{\circ} \mathrm{C}$ in presence of suitable activating agent such as steam, nitrogen, oxygen etc[7-9].

Preparation of activated carbon using chemical and physical activation has been widely studied using different synthetic polymer materials such as viscous rayon [10], polyacrylonitrile (PAN) [11], polyfurfuryl alcohol [12] and phenolic resin [13] followed by activation of the chars obtained. The production of activated carbon with desired pore size distribution and surface chemistry from low cost precursor is an important challenge. Polymer Blend method is one such method that enable synthesis of porous carbon of desired pore size and pore size distribution from two polymers of different thermal stability.

Earlier we reported the preparation of activated carbon from stabilized poly-blend ${ }^{14}$. In the present studies, stabilized poly-blend was carbonized and activated with steam in one step and 
effect of activation temperatures on surface characteristics was studied. The weight-loss behavior during steam activation of stabilized poly-blend at different temperatures, surface area and pore size distribution were studied to identify the optimum synthesis parameters. With optimized parameters these studies could help to develop activated carbon of desired pore size with narrow pore size distribution for specific applications.

\section{Experimental}

\subsection{Raw materials}

Novolac type phenol formaldehyde resin and polymethylmethacrylate (PMMA) were used as precursor materials for preparation of activated carbon [14].

\subsection{Carbonization and activation}

Stabilized poly-blend of PMMA and Novolac was carbonized in nitrogen atmosphere at different temperatures for an hour in an electrically heated furnace followed by activation at different temperatures in steam under controlled steam rate to enhance its surface area and porosity.

Dried sample of the stabilized poly-blend was placed in the heating zone of electric furnace in nitrogen atmosphere. Flow rate of steam was controlled at $0.2 \mathrm{ml} / \mathrm{min}$. Flow of steam and nitrogen mixture through the sample was maintained throughout the process. At various temperatures i.e. $800,850,900,950$ and $1150^{\circ} \mathrm{C}$, after an hour of hold time in an inert atmosphere (for carbonization), steam was passed for activation, thereby performing one step carbonization \& activation reaction.

\section{Characterization}

\section{$3.1 \%$ Yield}

The carbon \%yield obtained at different activation temperatures are shown in Fig. 1. It can be seen that as temperature of activation is raised, the carbon yield \%, get decreased as some surface and loosely bounded carbon atoms get oxidized to carbon dioxide and get removed leaving behind highly porous structure.

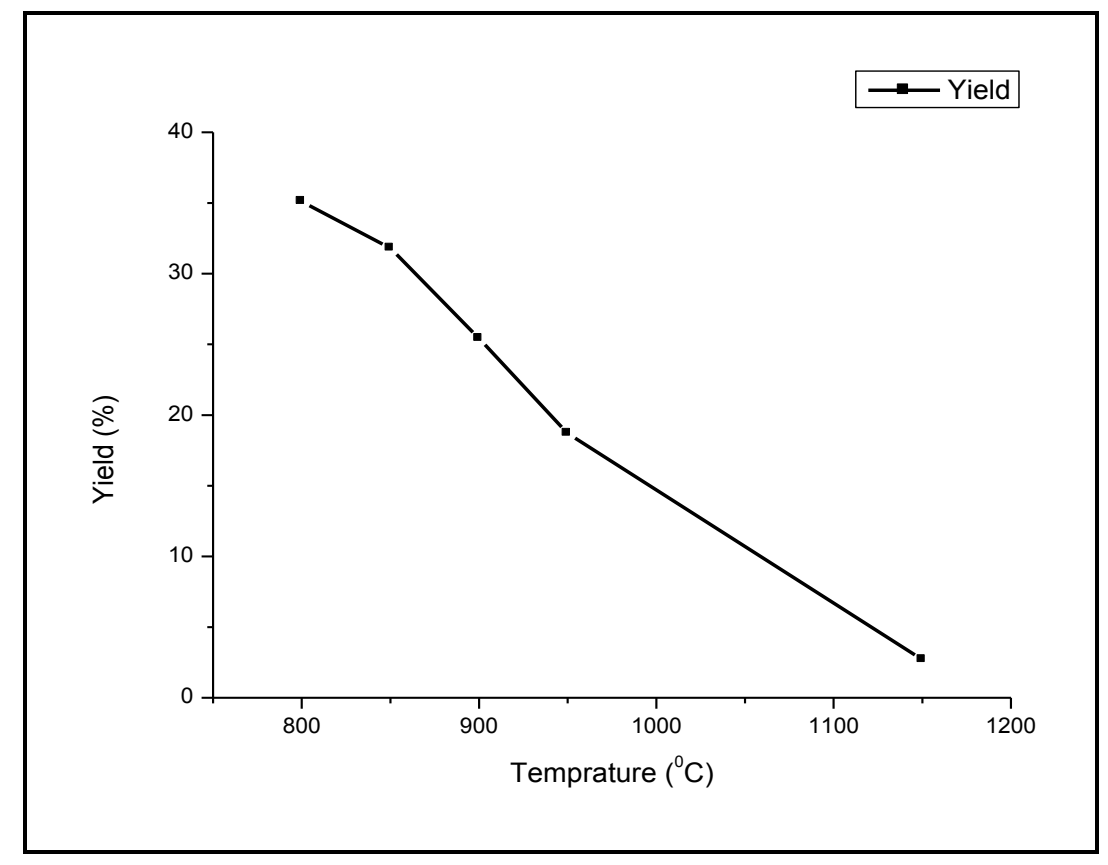

Fig. 1. \% carbon yield after steam activation at different activation temperature powder.

When activation is carried out at high temperature, burn off is higher and obtained carbon percentage get reduced. Therefore, as activation temperature increases, carbon yield decreases. 
During steam activation, sample undergoes weight loss on account of loss of amorphous carbon. With the removal of amorphous carbon, pores open up and become available for the adsorption process and therefore surface area increases.

\subsection{Surface Characteristics}

The surface characteristics i.e., surface area, pore size, pore size distribution were determined by BET, Micromeritics Gemini-2375 Instruments. The samples were cleaned at $100{ }^{\circ} \mathrm{C}$ in presence of Argon gas for 1 hour at $250^{\circ} \mathrm{C}$ for 12 hours. The $\mathrm{N}_{2}$ adsorption was studied at liquid nitrogen temperature $\left(-196^{\circ} \mathrm{C}\right)$.

The shape of these plots except sample activated at $1150^{\circ} \mathrm{C}$ is matching with 'type I' of having six principal classes of isotherm shapes as shown in figure 1. These isotherms showmicroporous nature of carbon having maximum adsorption of nitrogen gas at low relative pressure i.e. adsorption of nitrogen gas at liquid nitrogen temperature onto activated carbons, initially filling of micropores occurs at lower relative pressure and results in type I adsorption isotherms which are characteristics of microporous materials. The volume of nitrogen adsorbed is seen to be increasing with increasing activation temperature, being highest for sample activated at $1150^{\circ} \mathrm{C}$ and minimum for sample activated at $800^{\circ} \mathrm{C}$.

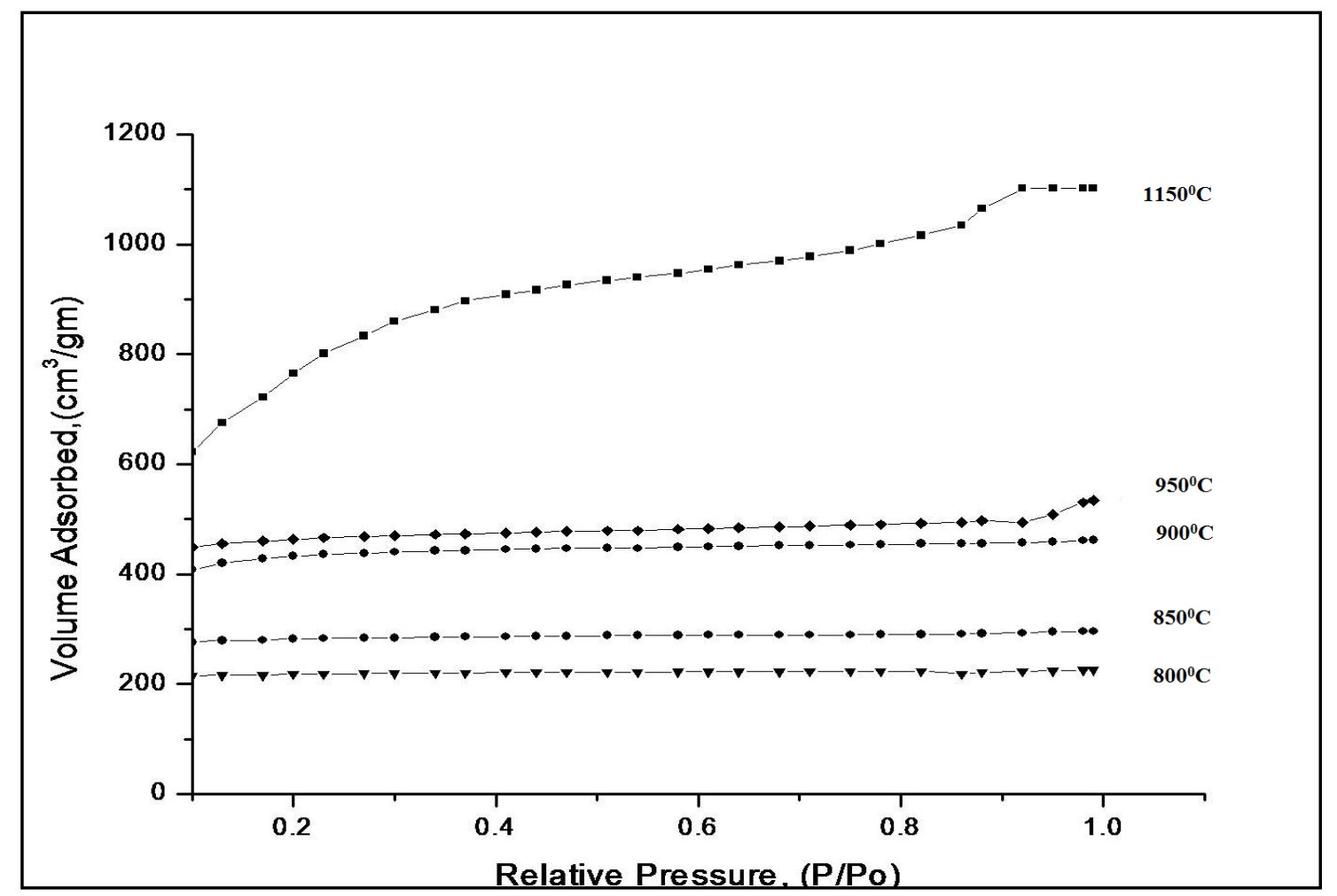

Fig. 2. Adsorption and desorption isotherms of the activated carbon samples.

The comparisons of surface characteristics of activated carbons activated at different temperatures are given in Table 1. It shows an increase in surface area from $877 \mathrm{~m}^{2} / \mathrm{gm}$ to $2814 \mathrm{~m}^{2} / \mathrm{gm}$ with increasing activation temperatures from $800^{\circ} \mathrm{C}$ to $1150^{\circ} \mathrm{C}$, while percentage micro porosity decreases from 92 to 19 percentages with increasing activation temperature during activation process. As the temperature of activation is raised, the pore walls collapse resulting in enlarging their pore size. Results show micro porous nature of activated carbon prepared at low temperature. But with increase in the activation temperature, there was slight increase in the adsorbed volume at higher relative pressure which indicates that microporosity shifts towards the mesoporosity. The sample steam activated at $800^{\circ} \mathrm{C}$ has maximum microporosity and sample activated at $1150^{\circ} \mathrm{C}$, has only $19 \%$ microporosity. 
Table 1. Surface characteristics of Activated carbon samples developed in one step.

\begin{tabular}{|c|c|c|c|c|c|c|c|}
\hline No & $\begin{array}{c}\text { Activation } \\
\text { temperature } \\
\left({ }^{\circ} \mathrm{C}\right)\end{array}$ & $\begin{array}{c}\text { Activation } \\
\text { time } \\
\text { (min) }\end{array}$ & $\begin{array}{c}\text { Burn } \\
\text { off, } \\
\%\end{array}$ & $\begin{array}{c}\text { Average } \\
\text { pore } \\
\text { diameter( }(\AA)\end{array}$ & $\begin{array}{c}\text { BET } \\
\text { Surface } \\
\text { area } \\
\left(\mathrm{m}^{2} / \mathrm{g}\right)\end{array}$ & $\begin{array}{l}\text { Micropore } \\
\text { area }\left(\mathrm{m}^{2} / \mathrm{g}\right)\end{array}$ & $\begin{array}{c}\% \\
\text { micropores } \\
\text { area }\end{array}$ \\
\hline 1 & 800 & 60 & 65 & 15.91 & 877.29 & 812.81 & 92.58 \\
\hline 2 & 850 & 60 & 68 & 16.54 & 1110.45 & 1015.68 & 91.44 \\
\hline 3 & 900 & 60 & 75 & 17.37 & 1446.93 & 1249.23 & 87.68 \\
\hline 4 & 950 & 60 & 82 & 18.60 & 1764.96 & 1514.88 & 85.82 \\
\hline 5 & 1150 & 60 & 97 & 24.23 & 2814.85 & 538.41 & 19.12 \\
\hline
\end{tabular}

Table 1 shows that as surface area increases from $877 \mathrm{~m}^{2} / \mathrm{g}$ to $2814 \mathrm{~m}^{2} / \mathrm{gm}$ on different steam activation temperatures the average pore diameter increases from $15.91 \AA$ to $24.00 \AA$. These results show the effect of activation temperatures on the properties of activated carbon. As the activation temperature is increased, the BET surface area and average pore diameter also increase. This may be attributed to the development of new pores due to collapse of weak pore boundaries as a result of release of volatile matters and widening of existing pores as the activation temperature is raised. The variation of surface area with steam activation temperature is given in Fig. 3.

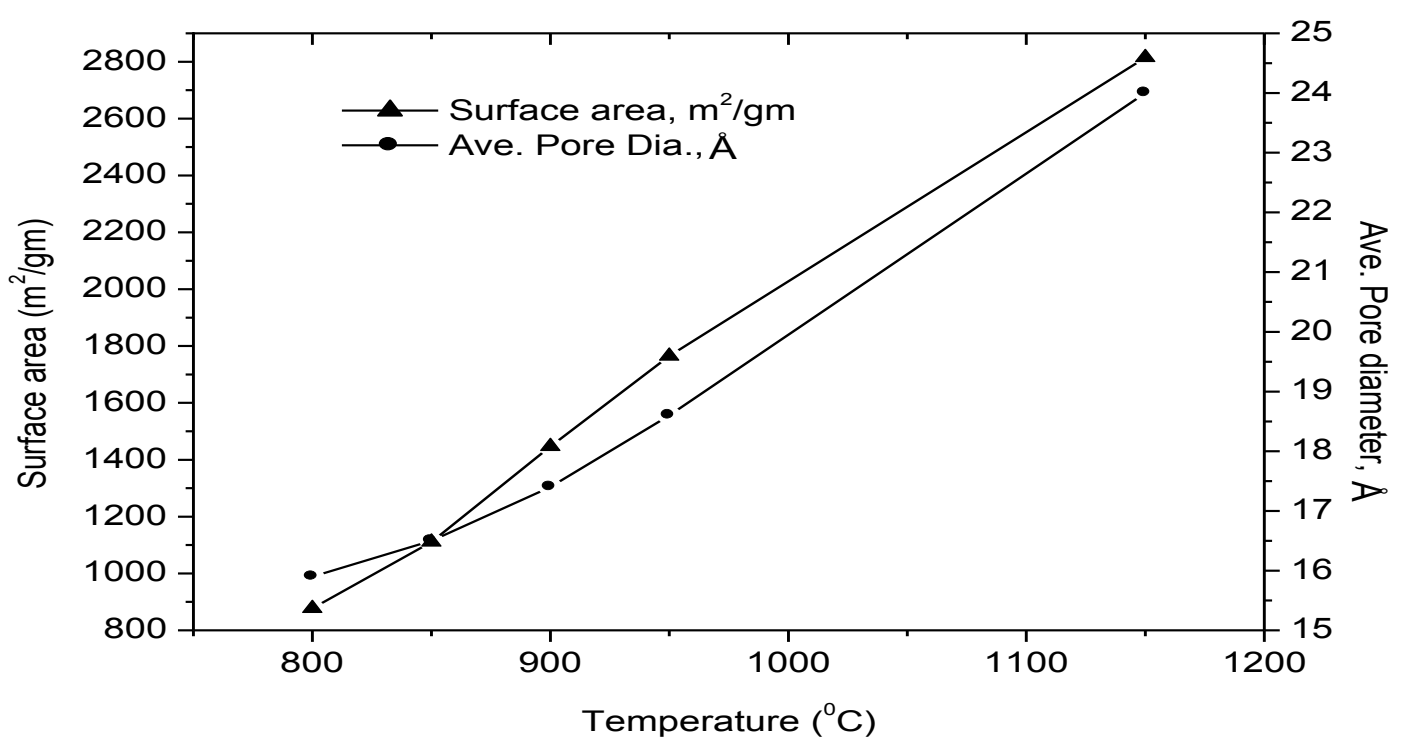

Fig 3. Effect of activation temperature on BET surface area and average pore diameter. 
Table 2. Surface characteristics of Activated carbon samples developed in two steps.

\begin{tabular}{|c|c|c|c|c|c|c|}
\hline No & $\begin{array}{c}\text { Activation } \\
\text { temperature } \\
\left({ }^{\circ} \mathbf{C}\right)\end{array}$ & $\begin{array}{c}\text { Activation } \\
\text { time } \\
(\mathbf{m i n})\end{array}$ & $\begin{array}{c}\text { Burn off, } \\
\mathbf{\%}\end{array}$ & $\begin{array}{c}\text { BET Surface } \\
\text { area }\left(\mathbf{m}^{2} / \mathbf{g}\right)\end{array}$ & $\begin{array}{c}\text { Micropore } \\
\text { area }\left(\mathbf{m}^{2} / \mathbf{g}\right)\end{array}$ & $\begin{array}{c}\% \\
\mathbf{m i c r o p o r e s} \\
\text { area }\end{array}$ \\
\hline 1 & 800 & 60 & 70 & 762.17 & 695.42 & 91.24 \\
\hline 2 & 850 & 60 & 73 & 952.21 & 861.71 & 90.12 \\
\hline 3 & 900 & 60 & 75 & 1116.28 & 1011.90 & 90.65 \\
\hline 4 & 950 & 60 & 80 & 1496.67 & 1244.62 & 83.16 \\
\hline 5 & 800 & 120 & 75 & 891.91 & 813.27 & 91.18 \\
\hline 6 & 850 & 120 & 75 & 1099.47 & 976.49 & 88.81 \\
\hline
\end{tabular}

The result of surface characteristics of activated carbon developed by single step method were given in Table 1 compared with surface characteristics of activated carbon developed by two step method in Table 2. It shows single step method gives higher surface area e.g. activated carbon at $850{ }^{\circ} \mathrm{C} / 1 \mathrm{hr}$., one step method gives $1110 \mathrm{~m}^{2} / \mathrm{gm}$, while two step method gives $952 \mathrm{~m}^{2} / \mathrm{gm}$. Similarly in one step method carbon yield is $32 \%$, while two steps shows $27 \%$.

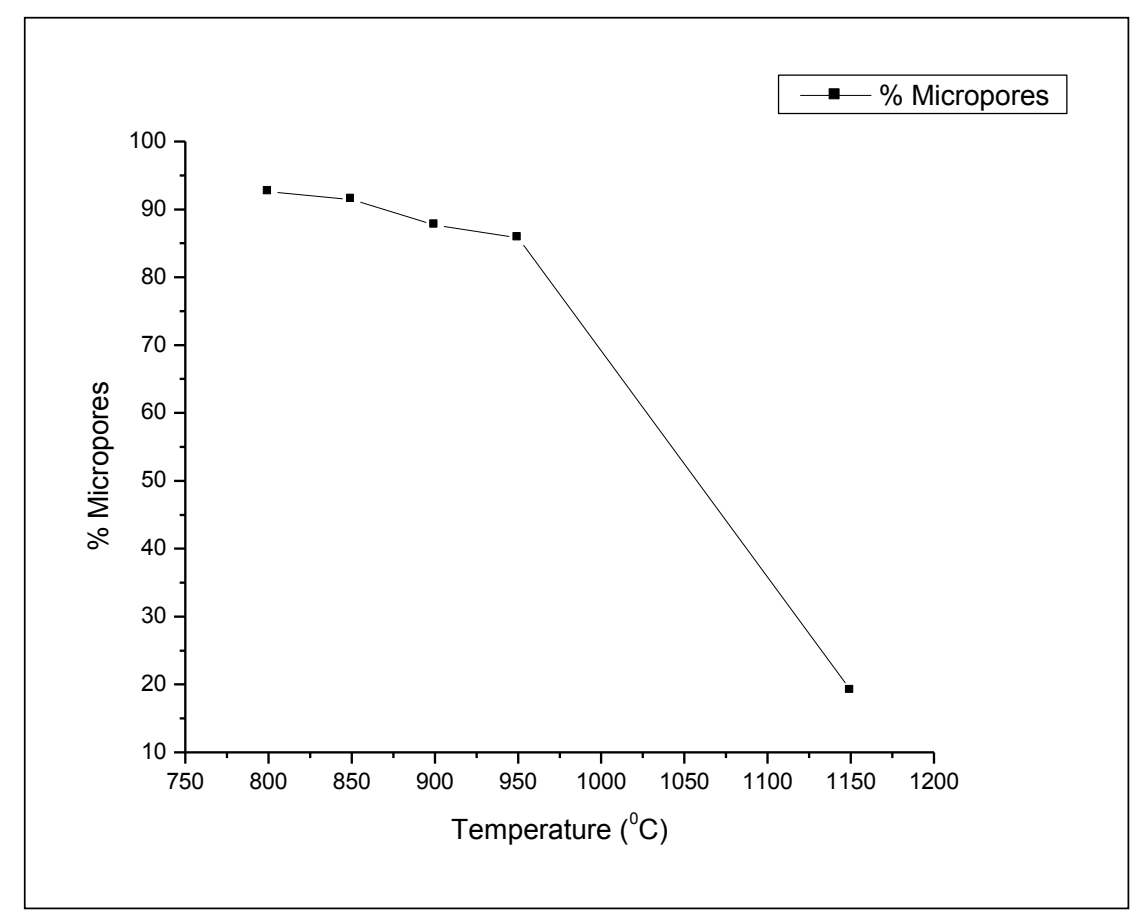

Fig. 4. Effect of activation temperature on micropore volume.

Fig. 4 shows microporosity volume \% generated at different activation temperatures. As activation temperature increases, $\%$ microporosity decreases. These results indicate that widening of micropores start on activation at higher temperature and these get converted into mesopores. In other words the microporosity is very sensitive to the change in activation temperature. From Fig. 3 and 4it can be concluded that the activation temperature plays an important role in controlling the BET surface area, percentage micropore and micropore volume of activated carbons. These results show that temperature of activation is important for formation of specific \& selected porosity. 

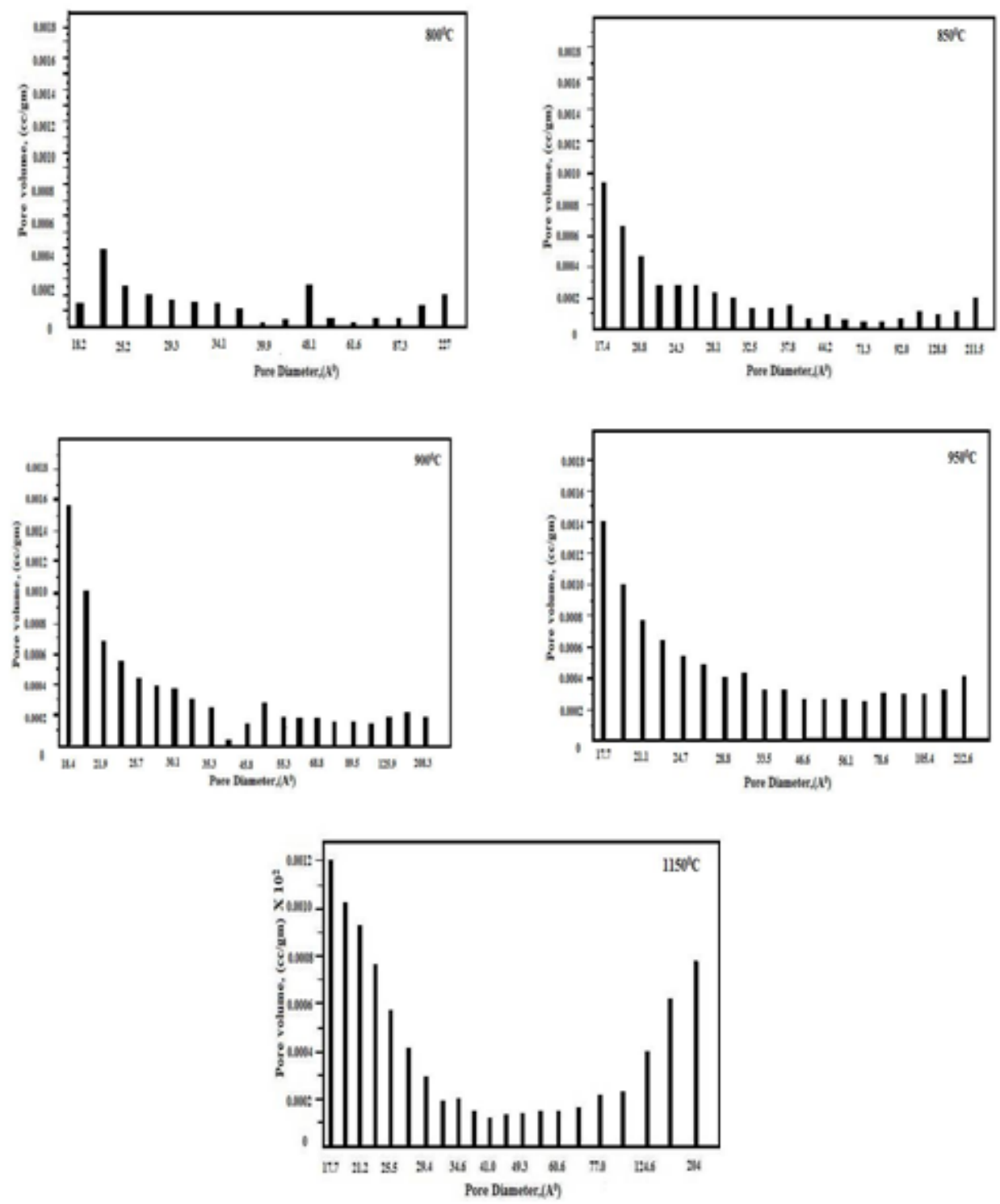

Fig. 5. Effect of heat treatment temperature on pore characteristics.

Elimination of amorphous carbon lead to opening of closed pores as indicated by pore size distribution graph (Fig 5). On increasing the activation temperature, the pores get widened to large size on account of gasification of carbon in the pore walls. From the figure it is apparent that as activation temperature is increased, the development of mesopores enhanced leading to development of mesoporous carbon. Thus, by controlling the processing parameters, highly microporous or mesoporous activated carbon can be developed.

\section{CONCLUSION}

Activated carbons were developed by carbonization and steam activation of stabilized polymer blend in single step at different temperatures between $800-1150^{\circ} \mathrm{C}$. Surface characterization results reveal that all powder samples were generally microporous in nature and surface area values were in the range of 877 to $2841 \mathrm{~m}^{2} / \mathrm{g}$. Results show that surface area of activated carbon samples increase with increase in the steam activation temperature. Burn off, \% during steam activation reaction increases as the temperature of the steam activation increases. With increase in steam activation temperature, $\%$ micropore area decreases as pore walls collapse at higher temperatures. A comparison of surface characterization revealed that of activated carbon prepared in single step has higher surface area and higher \% microporosity and more yield. Thus activated carbon with high percentage of desired porosity, surface area and carbon content can be developed by controlling the processing parameter. 


\section{Acknowledgement}

The author Dr. Parth Joshi wishes to thank University Grants Commission, India for providing the financial assistance under "UGC research fellowship for meritorious student scheme".

\section{REFERENCES}

[1] A.Kumar, S. Kumar, S. Kumar, Carbon,41 (2003)3015-3025.

[2] L.R. Radovic, I.F. Silva, J.I. Ume, J.A. Menendez, C. A. Leon, Carbon, 35 (1997) 1339-1348.

[3] D. Mohan, K.P. Singh, S. Sinha, D. Gosh, Carbon,42 (2004) 2409-2421.

[4] A. Bagreev, J.A. Menendez, I. Dukhno, Y. Tarasenko, T.J. Bendosz,Carbon,43 (2005)208210.

[5] A.A. Bagreev, W. Kuang, T.J. Bandosz, Adsorption,11, (2005) 461-466.

[6] K.L.Foster, R.G.Fuerman, J.Economy, S.M. Larson, M.J. Rood, Chemistry of materials,4(1992) 1068-1073.

[7] S.M. Manocha, H. Patel, L.M. Manocha,Prajna,18,(2010) 106-109.

[8] M.Molina-Sabio, M.Gonzalez, F.Rodriguez-Reinoso, A.Sepulveda-cribano,Carbon,34,(1996) 505-509.

[9] K. Tomkow, T. Siemieniewska, F. Czechowski, A. Jankowska, Fuel,56,(1977) 266-270.

[10] I.D. Harry, B. Saha, I.W. Cumming, Carbon, 45,(2007) 766-774.

[11] Z. Ryu, J. Zheng, M. Wang, Carbon, 36,(1998) 427-432.

[12] C.L. Burket, R. Rajagopalan, A.P. Marencic, K. Dronvajjala, H.C. Foley, Carbon, 44,(2006) 2957-2963.

[13] T.A. Centeno, A.B. Fuertes, Journal of Membrane Science, 160,(1999) 201-211.

[14] S. Manocha, A. Brahmbhatt, Carbon Letters, 12 (2011) 85-89. 